\title{
Multiple Chronic Conditions: Prevalence, Health Consequences, and Implications for Quality, Care Management, and Costs
}

\author{
Christine Vogeli, $P h D^{1,2}$, Alexandra E. Shields, $P h D^{1,2}$, Todd A. Lee, PharmD PhD 4,5, \\ Teresa B. Gibson, $P h D^{3}$, William D. Marder, $P h D^{3}$, Kevin B. Weiss, MD MPH ${ }^{4,5}$, \\ and David Blumenthal, MD MPP ${ }^{1,2}$
}

'Institute for Health Policy in the Department of Medicine, Massachusetts General Hospital, Boston, MA, USA; ${ }^{2}$ Harvard Medical School, Boston, MA, USA; ${ }^{3}$ Thomson Healthcare, Ann Arbor, MI, USA; ${ }^{4}$ Institute for Healthcare Studies, Feinberg School of Medicine, Northwestern University, Chicago, IL, USA; ${ }^{5}$ Center for Complex Chronic Care, Hines VA Hospital, Hines, IL, USA.

Persons with multiple chronic conditions are a large and growing segment of the US population. However, little is known about how chronic conditions cluster, and the ramifications of having specific combinations of chronic conditions. Clinical guidelines and disease management programs focus on single conditions, and clinical research often excludes persons with multiple chronic conditions. Understanding how conditions in combination impact the burden of disease and the costs and quality of care received is critical to improving care for the 1 in 5 Americans with multiple chronic conditions. This Medline review of publications examining somatic chronic conditions co-occurring with 1 or more additional specific chronic illness between January 2000 and March 2007 summarizes the state of our understanding of the prevalence and health challenges of multiple chronic conditions and the implications for quality, care management, and costs.

KEY WORDS: chronic disease; comorbidity; prevalence; quality of health care.

J Gen Intern Med 22(Suppl 3):391-5

DOI: $10.1007 / \mathrm{s} 11606-007-0322-1$

(c) Society of General Internal Medicine 2007

\section{INTRODUCTION}

Typically, we study experience with health care conditions, including health care costs and quality, as if these conditions occur in isolation, one at a time. The vast majority of extant clinical guidelines and disease management programs focus on a single condition, although the experience of multiple chronic illnesses is the reality for many patients-particularly among the elderly and near elderly. The Institute of Medicine's report "Crossing the Quality Chasm" highlights the problem with health system fragmentation and stresses the need for health care systems that promote continuity of care and

The authors are members of the Consortium on Complex Chronic Illness, Quality, and Equity. The Consortium, directed by Dr. A. Shields, is a collaboration of investigators from Harvard, MGH, Northwestern, the VA, Thomson Healthcare, and Ingenix committed to accelerating research on complex chronic illness and its implications for quality and the health of vulnerable populations. integration of services. ${ }^{1}$ Realigning the focus of health services research to be more in line with the complex experience of patients is central to developing solutions that work. This paper provides information on what we know about multiple chronic conditions, specifically the prevalence and health challenges of multiple chronic conditions, and the ramifications of specific combinations of chronic conditions on quality, patient management, and costs.

\section{METHODS}

We performed a semistructured literature review to identify relevant articles. Specifically, we queried MEDLINE for peerreviewed publications that examined the prevalence, outcomes, costs, and patient management challenges associated with multiple chronic conditions.

We first selected all articles the Mesh terms 'chronic disease' and 'comorbidity,' and limited our search to articles on adults published in English between January 2000 and March 2007 $(n=643)$. This set was further paired down using 2 different strategies. The first strategy used a set of specific Mesh terms related to prevalence, quality, access, delivery of care, patterns of care, morbidity, mortality, and expenditures. To ensure that we did not overlook any important articles in the original set, we also limited the original set to articles published in core journals. The final set of 123 articles was the union of abstracts gained from these 2 approaches. Articles without abstracts or whose author was anonymous were not reviewed. The remaining abstracts were reviewed by the first author and abstracts that did not mention at least 1 specific somatic chronic illness, abstracts that did not examine specific comorbidities, and articles that focused on an acute illness or procedure were removed. Information summarized in this review stem from the remaining articles and prior publications cited by these articles.

\section{PREVALENCE OF MULTIPLE CHRONIC CONDITIONS}

The number of persons in the United States who have not just a single chronic condition, but multiple co-occurring chronic conditions is large and growing. In $2005,21 \%$ or roughly 63 million Americans had more than 1 chronic condition, or multiple illnesses or impairments expected to last a year or 
longer. A persons' risk of having more than 1 chronic condition, henceforth referred to as multiple chronic conditions or MCC, increases with age: $62 \%$ of Americans over 65 have MCC. With the aging of the US population, the number of Americans with MCC is projected to be 81 million by $2020 .^{2}$ The Institute of Medicine's seminal report "Crossing the Quality Chasm" noted that 23\% of Medicare beneficiaries have 5 or more chronic conditions. ${ }^{1}$

Prior research has documented the prevalence of individual conditions in the U.S. population generally and among the elderly and near elderly in particular. For example, based on data from the Medicare Current Beneficiary Survey (MCBS), the most prevalent individual conditions among the over-65 population include: arthritis (57\%), hypertension (55\%), pulmonary disease $(38 \%)$, diabetes $(17 \%)$, cancer $(17 \%)$ and osteoporosis (16\%). ${ }^{2}$ However, there has been very little research to date exploring the prevalence of particular combinations or clusters of chronic conditions, and almost all studies examining specific comorbidities do so from the perspective of a specific index disease rather than examining all co-occurring chronic conditions. ${ }^{3}$

Only a fragmentary portrait of the prevalence of MCC emerges from studies examining comorbidities among patients with specific index conditions. A case-control study of asthmatics found that diabetes was more common in concert with asthma, but obesity was more common in patients without asthma ${ }^{4}$ Of patients with Alzheimer's disease, $28 \%$ also have congestive heart failure, $27 \%$ chronic obstructive pulmonary disease, $22 \%$ diabetes mellitus, and $20 \%$ cancer. $^{2}$ In comparison to the general population, persons receiving care for schizophrenia or affective disorders in community-based treatment centers were more likely to suffer from asthma, chronic bronchitis, diabetes, and liver problems. ${ }^{5}$ Finally, persons suffering from epilepsy have higher rates of a host of chronic conditions, including bowel disorders, bronchitis/emphysema, heart disease, and stroke in comparison to the general population. ${ }^{6}$

Fewer studies have explored the natural clustering of chronic conditions. Using cross-sectional Medicare claims data, Wolff and colleagues grouped a national sample of Medicare patients into Major Diagnostic Categories (MDC) based on a well-validated grouping algorithm. They found that the tendency of patients to have comorbid conditions varied from $80 \%$ among individuals in the MDC "myeloproliferative disorders" to $32 \%$ in the "circulatory disorders" MDC. These investigators found that specific combinations of chronic conditions occurred more frequently than expected, and proposed that perhaps underlying biological vulnerabilities may help explain the clustering of diseases within individuals. ${ }^{7}$ A subsequent more limited study used cluster analysis to identify conditions that tend to co-occur among elderly American Indians. The specific conditions in this group include heart disease, stroke, hypertension, diabetes, urinary or bladder conditions, and tuberculosis. Interestingly, although arthritis is 1 of the 2 most common chronic conditions in this population, it does not commonly occur in concert with other conditions. ${ }^{8}$

Perhaps the most widely known example of the clustering of chronic conditions in a biologically and clinically meaningful way is the so-called metabolic syndrome. Found in $24 \%$ of the U.S. population, ${ }^{9}$ the metabolic syndrome is present when patients have at least 3 of 5 chronic conditions: obesity, hypertriglyceridemia, low-serum high-density lipoprotein
(HDL), hypertension, and glucose intolerance. ${ }^{10,11}$ The metabolic syndrome is associated with increased risk of cardiovascular disease and all cause mortality ${ }^{12,13}$ and may reflect underlying genetic predispositions to this combination of chronic conditions. ${ }^{14,15}$

\section{HEALTH CONSEQUENCES}

The health consequences of multiple chronic conditions are poorly understood. Overall, specific chronic conditions have a stronger relationship with functional impairment than others, and persons with more chronic conditions become more functionally impaired sooner than persons with fewer chronic conditions. ${ }^{16}$ The picture, however, appears to be more complex. One of the most revealing studies to date found that after controlling for the presence of individual conditions, specific MCC were associated with disability far greater than expected based on the disability observed for each disease in isolation. The authors suggested that some diseases may be associated with disability only in the presence of other specific diseases, and that "a new, potentially effective strategy for prevention or amelioration of disability would be to decrease targeted disease-disease interactions". ${ }^{17}$ Fultz et al. ${ }^{18}$ also found synergistic interactions between some pairings of mental and physical conditions, but not others. For example, persons with stroke and cognitive impairment had a higher level of impairment in activities of daily living than predicted by the presence of stroke and cognitive impairment alone. Other combinations, such as stroke and depression, did not have the same synergistic effect on activities of daily living impairments. ${ }^{18}$ A recent analysis of near-elderly veterans found that in general the risk of 5-year mortality increased with the number of co-occurring chronic conditions; however, osteoarthritis in combination with any other chronic condition actually lowered the risk of 5-year mortality. ${ }^{19}$

\section{QUALITY AND CARE MANAGEMENT CHALLENGES}

Persons with multiple chronic conditions are particularly vulnerable to suboptimal quality care. ${ }^{2}$ They tend to use services more frequently and to use a greater array of services than other consumers of care. This makes coordination of care more difficult for individuals with multiple chronic conditions. The number of different physicians seen annually by the average Medicare patient with a chronic condition ranges from 4 with 1 condition to 14 with 5 or more. As the number of providers involved in patients' care increases, patients are likely to find it increasingly challenging to understand, remember, and reconcile the instructions of those providers. ${ }^{20}$ Because patients with more than 1 chronic condition take on average more medications, they are more likely to suffer adverse drug events (ADEs), including ADEs that result from drug-drug interactions, ${ }^{21-24}$ or in the specific case of heart failure coupled with chronic obstructive pulmonary disease, present challenges to appropriate pharmacological management. ${ }^{25}$ Having multiple chronic conditions also makes it more challenging for patients to participate effectively in their own care. ${ }^{26}$ Surveys of physicians confirm that they believe quality problems are increased among their patients with multiple chronic conditions. ${ }^{27}$ 
However, the link between co-occurring chronic conditions and poor quality is far from clear. An assessment of quality among Canadians over 65 with specific combinations of chronic conditions found deficiencies in care associated with some combinations of conditions, but not all. For example, patients with hyperlipidemia and chronic obstructive pulmonary disease were less likely than patients with hyperlipidemia alone to receive lipid-lowering medications. Individuals with psychoses and arthritis were less likely to receive arthritis medications than individuals with arthritis alone. However, glaucoma patients with breast cancer are no less likely to receive glaucoma medications than those without breast cancer. $^{28}$ A well-known study of the predictors of initiating psychiatric treatment found that "competing demands" from physical problems hindered the initiation of psychiatric care. ${ }^{29}$ However, other studies have found that co-occurring chronic conditions are actually associated with more appropriate care. Contrary to prior expectations, researchers examining a cohort of diabetic patients enrolled in a heart failure disease management program found that despite their targeted heart failure care, these patients also received comprehensive diabetes care. ${ }^{30}$ Patients with somatic chronic conditions may actually receive more appropriate care for depression or other psychiatric disorders. Among elderly persons, depression care was more likely to be adequate among elderly persons with cooccurring diabetes than without, ${ }^{31}$ and neither the number nor specific comorbid conditions were found to impact the effectiveness of interventions aimed at improving depression care. ${ }^{32}$

More general measures of quality also yielded mixed results. Braunstein et al. ${ }^{33}$ found that the occurrence of hospitalizations for ambulatory care sensitive conditions increased among elderly heart failure patients when they suffered from other comorbidities. Hospitalizations for ambulatory care sensitive conditions are considered preventable by good primary care. ${ }^{34}$ The odds of experiencing these so-called "preventable" hospitalizations were largest when heart failure occurred in combination with hypertension or chronic renal insufficiency. However, for unknown reasons, certain comorbidities, such as hypercholesterolemia or dementia, seemed to protect heart failure patients against hospitalization for ambulatory care sensitive conditions. ${ }^{33}$ Among vulnerable persons age 65 and over, Min et al. ${ }^{35}$ found that overall, persons with more chronic conditions had higher (better) risk-adjusted quality scores. However, specific combinations such as diabetes and cardiovascular disease were associated with worse quality of care as measured by a composite of up to 207 quality indicators.

It is reasonable to hypothesize that clinicians systematically vary in the provision of indicated services when caring for patients with particular combinations of conditions, just as they systematically overlook certain issues in caring for single illnesses. ${ }^{36}$ For example, systematic differences in colon cancer screening rates among elderly persons with chronic conditions may reflect conscious decisions to concentrate screening on patients whose life expectancy can be improved through cancer treatment. ${ }^{37}$

Several observers have argued that current strategies including disease-specific health guidelines may not be suitable in many cases to optimizing care of individuals with MCC. ${ }^{21,24}$ Instead, it is argued, guidelines need to be tailored to clusters of illnesses in ways that acknowledge not only the biology of those clusters, but also the special challenges and threats to quality of care associated with MCC in general and specific clusters in particular. Moreover, single-disease-oriented disease management programs, which frequently offer services provided outside traditional health care facilities (call centers and coaches, for example), have the potential to further fragment care. Even Wagner's Chronic Care Model, which emphasizes coordination of care around chronic illness, focuses primarily on single illnesses, not multiple chronic conditions, ${ }^{38}$ so that its relevance and effects on multiple chronic conditions remain to be explored.

The intrinsic challenges to optimizing quality and value of care among individuals with multiple chronic conditions, the evidence that quality may be suboptimal for some individuals with multiple chronic conditions, and indications that quality may vary with the specific clusters of chronic conditions, all suggest the need to explore more systematically the relationship between quality of care and clusters of chronic conditions.

\section{COSTS OF CARE}

In a country with health care expenditures exceeding $\$ 1.7$ trillion and $15 \%$ of gross domestic product, ${ }^{39}$ controlling costs of care has become an overwhelming concern among public and private policy makers and managers. From this perspective, individuals with multiple chronic conditions pose special challenges and opportunities. The care of individuals with chronic conditions is estimated to account for $78 \%$ of health expenditures in the United States. Patients with more than 1 chronic condition are estimated to account for 95\% of all Medicare spending; those with more than 5 account for two thirds. ${ }^{2}$ The Congressional Budget Office reports that among high-cost Medicare beneficiaries (e.g., the $25 \%$ of beneficiaries accounting for $85 \%$ of programmatic costs), about $30 \%$ had 4 co-occurring chronic illnesses: coronary artery disease, diabetes, congestive heart failure, and chronic obstructive pulmonary disease. ${ }^{40}$ The likelihood that patients with a particular condition such as heart failure or diabetes will use expensive health care resources such as hospital care increases substantially with the presence of other comorbidities. ${ }^{33,41}$ For example, the likelihood that a Medicare patient with a chronic medical condition will use emergency department services doubles when depression is present as a comorbidity. ${ }^{42}$ Medicare beneficiaries with heart failure who have comorbidities are more likely to be readmitted for heart failure than patients without comorbidities. ${ }^{43}$

The concentration of health care expenditures in subpopulations with chronic conditions has led to the widespread proliferation of disease management programs. In 2004, 97\% of private health plans had disease management programs for diabetes, $86 \%$ for asthma, $83 \%$ for heart failure, and $70 \%$ for ischemic heart disease. ${ }^{44}$ State Medicaid programs have also begun implementing similar disease management programs. ${ }^{45,46}$ Under provisions of the Medicare Modernization Act, Congress instructed the Centers for Medicare and Medicaid Services to undertake a variety of initiatives to improve care for high-cost, chronically ill patients, including the Chronic Care Improvement Program (CCIP), a large national experiment with applying disease management programs to patients in the traditional Medicare program. ${ }^{47,48}$ The CCIP will target more than 30,000 beneficiaries with 3 conditions (diabetes, 
heart failure, and chronic obstructive pulmonary disease) in 10 regions of the country.

Despite the conceptual attractiveness of the disease management approach, evidence of clinical and cost-effectiveness remain limited. ${ }^{49,50}$ Recent analyses have found that cost savings and return on investments varied by diagnosis. ${ }^{51,52}$ Most disease management programs focus on management of a single chronic condition. This raises concerns about whether they may undermine coordination of care for patients with $\mathrm{MCC},{ }^{53}$ thereby introducing new inefficiencies and potential threats to quality of care. ${ }^{21,24,54}$ Furthermore, by focusing on a single illness, programs fail to account for the synergistic impact of chronic conditions occurring in combination. The Medicare program has begun experimenting with improving management of patients with MCC under other demonstrations including its Medicare Coordinated Care Demonstration and its Care Management for High-Cost Beneficiaries Demonstration. More recently, some private health plans have also shifted toward intensive case management programs aimed at highrisk patients with multiple complex conditions, ${ }^{50}$ often using predictive modeling applications to identify members whose past utilization suggests they are likely to generate high health care costs in the future. ${ }^{55}$ However, even these initiatives may suffer from the fact that they lack information necessary to take into account the potential variation in costs and quality associated with particular MCC and information on the most efficacious treatments for specific disease combinations.

\section{CONCLUSION}

Understanding how to care effectively for persons with multiple chronic conditions is among the most important challenges our health care system faces. Despite the depth of research into specific chronic conditions, there is little information about the prevalence of MCC, and the health and cost impacts of specific combinations of chronic conditions. The small amount we do know suggests that specific chronic conditions combine and impact health and costs in unpredictable ways, and that specific combinations have particularly large impacts of health or costs of care.

Currently, there are a number of methodological challenges to research on MCC, including, fundamentally, the need for large and preferably longitudinal, clinically meaningful data that can be used to identify the natural history of disease, and control for the severity of individual conditions when assessing outcomes for MCC. The increasing adoption of health information technology has the potential to greatly improve the level of clinical detail of widely available data, ${ }^{56}$ and may help accelerate clinically meaningful research.

Such research should help illuminate why certain clusters of comorbid illness may be more prone to quality lapses or be associated with significant but unexpected clinical outcomes, and lead to the development of targeted strategies, including tailored MCC-specific clinical guidelines, to improve the management of patients with key MCC. Similarly, research on more clinically detailed data may be used to develop computerized decision support that incorporates new knowledge regarding the additive clinical impact of specific comorbidities co-occurring within a patient and anticipate the tendency of clinicians to overlook or overprescribe certain elements in the process of care. Although payers have begun to target high cost combina- tions, far more research is needed to understand the clinical impact of the clustering of chronic illness and to incorporate this more refined understanding into targeted quality improvement and clinical management strategies. With the aging of population, these needs are ever more pressing.

Acknowledgments: No authors received funding, either internal or external, to support this work.

Conflicts of interest: None disclosed.

Corresponding Author: Christine Vogeli, $\mathrm{PhD}$; Institute for Health Policy in the Department of Medicine, Massachusetts General Hospital, 50 Staniford Street, 9th Floor, Boston, MA 02114, USA (e-mail: cvogeli@partners.org).

\section{REFERENCES}

1. Committee on Quality of HealthCare in America, Institute of Medicine. Crossing the Quality Chasm: A New Health System for the 21st century. Washington D.C.: National Academies Press; 2001.

2. Partnership for Solutions. Chronic Conditions: Making the Case for Ongoing Care: Robert Wood Johnson Foundation; 2002.

3. Gijsen R, Hoeymans N, Schellevis FG, Ruwaard D, Satariano WA, van den Bos GA. Causes and consequences of comorbidity: a review. J Clin Epidemiol. 2001;54(7):661-74.

4. Ben-Noun L. Characteristics of comorbidity in adult asthma. Public Health Rev. 2001;29(1):49-61.

5. Sokal J, Messias E, Dickerson FB, Kreyenbuhl J, Brown CH, Goldberg RW. Comorbidity of medical illnesses among adults with serious mental illness who are receiving community psychiatric services. J Nerv Ment Dis. 2004;192(6):421-7.

6. Tellez-Zenteno JF, Matijevic $\mathbf{S}$, Wiebe $\mathbf{s}$. Somatic comorbidity of epilepsy in the general population in Canada. Epilepsia 2005;46 (12):1955-62.

7. Wolff JL, Starfield B, Anderson GF. Prevalence, expenditures, and complications of multiple chronic conditions in the elderly. Arch Intern Med. 2002;162:2269-76.

8. John R, Kerby DS, Hennessy CH. Patterns and impact of comorbidity and multimorbidity among community-resident American Indian elders. Gerontologist 2003;43(5):649-60.

9. Park YW, Palaniappan L, Heshka S, Carnethon MR, Heymsfield SB. The metabolic syndrome: prevalence and associated risk factor findings in the US population from the Third National Health and Nutrition Examination Survey, 1988-1994. Arch Intern Med. 2003;163(4):427-36

10. Ford ES, Giles WH, Dietz WH. Prevalence of the metabolic syndrome among US adults: findings from the Third National Health and Nutrition Examination Survey. J Am Med Assoc. 2002;287(3):356-9.

11. Grundy SM, Brewer HB, Cleeman JI, Smith SC, Lenfant C. Definition of metabolic syndrome: Report of the National Heart, Lung, and Blood Institute/American Heart Association Conference on Scientific Issues Related to Definition. Circulation 2004;109:433-8.

12. Hu G, Giao Q, Tuomilehto J, Balkau B, Borch-Johnsen K, Pyorala K. Prevalence of the metabolic syndrome and its relation to all-cause and cardiovascular mortality in nondiabetic European men and women. Arch Intern Med. 2004;164(10):1066-76.

13. Lakka HM, Laaksonen DE, Lakka TA, et al. The metabolic syndrome and total and cardiovascular disease mortality in middle-aged men. JAMA 2002;288(21):2709-16.

14. Guettier JM, Georgopoulos A, Tsai MY, et al. Polymorphisms in the fatty acid-binding protein 2 and apolipoprotein C-III genes are associated with the metabolic syndrome and dyslipidemia in a South Indian population. J Clin Endocrinol Metab. 2005;90(3):1705-11.

15. Wyszynski DF, Waterworth DM, Barter PJ, et al. Relation between atherogenic dyslipidemia and the Adult Treatment Program-III definition of metabolic syndrome (Genetic Epidemiology of Metabolic Syndrome Project). Am J Cardiol. 2005;95(2):194-8.

16. Dunlop DD, Lyons JS, Manheim LM, Song J, Chang RW. Arthritis and heart disease as risk factors for major depression: the role of functional limitation. Med Care. 2004;42(6):502-11. 
17. Fried LP, Bandeen-Roche K, Kasper JD, Guralnik JM. Association of comorbidity with disability in older women: The Women's Health and Aging Study. J Clin Epidemiol. 1999;52(1):27-37.

18. Fultz NH, Ofstedal M, Herzog AR, Wallace RB. Additive and interactive effects of comorbid physical and mental conditions on functional health. J Aging Health. 2003; 15(3):465-84.

19. Lee TA, Pickard AS, Bartle B, Weiss KB. Osteoarthritis: a comorbid marker for longer life? Ann Epidemiol. 2007;17:380-4

20. National Academy of Social Insurance. Medicare in the 21st Century: Building a Better Chronic Care System. Washington, DC: National Academy of Social Insurance; 2003.

21. Boyd CM, Darer J, Boult C, Fried LP, Boult L, Wu AW. Clinical practice guidelines and quality of care for older patients with multiple comorbid diseases: implications for pay for performance. J Am Med Assoc. 2005;294(6):716-24.

22. Gandhi TK, Weingart SN, Borus $\mathbf{J}$, et al. Adverse drug events in ambulatory care. N Engl J Med. 2003;348(16):1556-64

23. Gurwitz JH, Field TS, Harrold LR, et al. Incidence and preventability of adverse drug events among older persons in the ambulatory setting. J Am Med Assoc. 2003;289(9):1107-16.

24. Tinetti ME, Bogardus ST, Agostini JV. Potential pitfalls of diseasespecific guidelines for patients with multiple conditions. N Engl J Med. 2004;351:2870-4

25. Le Jemtel TH, Padeletti M, Jelic S. Diagnostic and therapeutic challenges in patients with coexistent chronic obstructive pulmonary disease and chronic heart failure. J Am Coll Cardiol. 2007;49(2):171-80.

26. Townsend A, Hunt K, Wyke S. Managing multiple morbidity in mid-life: a qualitative study of attitudes to drug use. Br Med J 2003;327 (7419):837.

27. Anderson GF. Physician, public, and policymaker perspectives on chronic conditions. Arch Intern Med. 2003;163:437-42.

28. Redelmeier DA, Tan SH, Booth GL. The treatment of unrelated disorders in patients with chronic medical diseases. N Engl J Med. 1998;338(21):1516-20.

29. Nutting PA, Rost K, Smith J, Werner JJ, Elliot C. Competing demands from physical problems. Arch Fam Med 2000;9:1059-64.

30. Ware MG, Flavell CM, Lewis EF, Nohria A, Warner-Stevenson $\mathbf{L}$ Givertz MM. Heart failure and diabetes: collateral benefit of chronic disease management. Prev Manag Congest Heart Fail 2006;12 (3): $132-6$.

31. Harman JS, Edlund MJ, Fortney JC, Kallas H. The influence of comorbid chronic medical conditions on the adequacy of depression care for older Americans. J Am Geriatr Soc 2005;53(12):2178-83.

32. Harpole LH, Williams JW Jr, Olsen MK, et al. Improving depression outcomes in older adults with comorbid medical illness. Gen Hosp Psych 2005;27(1):4-12

33. Braunstein JB, Anderson GF, Gerstenblith G, et al. Noncardiac comorbidity increases preventable hospitalizations and mortality among Medicare beneficiaries with chronic heart failure. J Am Coll Cardiol. 2003;42(7): 1126-33

34. Kruzikas DT, Jiang HJ, Remus D, Barrett ML, Coffey RM, Andrews R. Preventable Hospitalizations: A Window into Primary and Preventive Care, 2000. Washington, DC: Agency for Healthcare Research and Quality; 2004.

35. Min LC, Reuben DB, MacLean CH, et al. Predictors of overall quality of care provided to vulnerable older people. J Am Geriatr Soc. 2005;53 (10):1705-11.

36. McGlynn EA, Asch SM, Adams J, et al. The quality of health care delivered to adults in the United States. N Engl J Med. 2003;348 (26):2635-45.
37. Gross CP, McAvay GJ, Krumholz HM, Paltiel AD, Bhasin D, Tinetti ME. The effect of age and chronic illness on life expectancy after a diagnosis of colorectal cancer: implications for screening. Ann Intern Med 2006;145(9):646-53.

38. Wagner EH, Austin BT, Von Korff M. Organizing care for patients with chronic illness. Milbank Quarterly 1996;74:511-44.

39. Smith C, Cowan C, Sensenig A, Catlin A. Health Accounts Team. Health spending growth slows in 2003. Health Affairs 2005;24(1): 184-94.

40. Congressional Budget Office. High Cost Medicare Beneficiaries. Washington, DC: The Congress of the United States; 2005

41. Niefeld M, Braunstein JB, Wu AW, Saudek CD, Weller W, Anderson GF. Preventable hospitalization among elderly Medicare beneficiaries with Type 2 diabetes. Diabetes Care 2003;26(5):1344-9.

42. Himelhoch S, Weller W, Wu AW, Anderson GF, Cooper LA. Chronic medical illness, depression, and use of acute medical services among Medicare beneficiaries. Med Care 2004;42(6):512-21.

43. Krumholz HM, Parent EM, Tu N, et al. Readmission after hospitalization for congestive heart failure among Medicare beneficiaries. Arch Intern Med. 1997;157(1):99-104.

44. Center on an Aging Society. Disease management programs: Improving health while reducing costs? Washington, DC: Georgetown University; 2004

45. Smith V, Ramesh R, Gifford K, Ellis E, Wachino V. States Respond to Fiscal Pressure: State Medicaid Spending Growth and Cost Containment in Fiscal Years 2004 and 2005: Results from a 50-state Survey. Washington, DC: The Henry J. Kaiser Family Foundation; 2004.

46. Sprague L. Disease Management to Population-Based Health: Steps in the Right Direction? National Health Policy Forum Issue Brief 2003;791:1-16

47. Glendinning D. New Medicare demo project focuses on chronic health care. American Medical News 2005; Government \& Medicine:5, 8

48. Gold M, Lake T, Black WE, Smith M. Challenges in improving care for high-risk seniors in Medicare: lessons and observations from past field demonstrations. Health Affairs 2005;Web Exclusive(26 April):W5-199W5-211.

49. Congressional Budget Office. An Analysis of the Literature on Disease Management Programs. Washington, DC: Congressional Budget Office; 2004 October 13

50. Short AC, Mays GP, Mittler J. Disease Management: A Leap of Faith to Lower-Cost, Higher-Quality Health Care. HSC Issue Brief 2003;No. 69

51. Bodenheimer T. Disease management in the American market. Br Med J 2000;320:563-6.

52. Goetzel R, Ozminkowski R, Villagra V, Duffy J. Return on investment in disease management: A review. Health Care Financ Rev 2005;26:1-19.

53. Blumenthal D, Beeuwkes Buntin M. Carve-outs for Medicare: Possible benefits and risks. In: Reischauer RD, Butler S, Lave JR, eds. Medicare: Preparing for the Challenges of the 21st Century. Washington, DC: National Academy of Social Insurance; 1998:152-83.

54. Von Korff M, Gruman J, Schaefer J, Curry SJ, Wagner EH. Collaborative management of chronic illness. Ann Intern Med. 1997;127 (12): 1097-102.

55. Mays GP, Claxton G, White J. Managed care rebound? Recent changes in health plans' cost containment strategies. Health Affairs 2004;Web Exclusive(W4):427-36.

56. Robert Wood Johnson Foundation, MGH Institute for Health Policy, George Washington University. Health Information Technology in the United States, the information base for progress; 2006, available at http: / /www.rwjf.org/files/publications/other/EHRReport0609.pdf (accessed July 17 2006). 